\title{
CONSTRUINDO O CONHECIMENTO ATRAVÉS DE PROJETOS DE TRABALHO: UMA EXPERIÊNCIA NO CURSO DE QUÍMICA DA UNIVERSIDADE ESTADUAL DE SANTA CRUZ
}

\author{
Edson José Wartha*, Neurivaldo José Guzzi Filho e Raildo Mota de Jesus \\ Departamento de Ciências Exatas e Tecnológicas, Universidade Estadual de Santa Cruz, Rodovia Ilhéus - Itabuna, km 16, \\ 45662-000 Ilhéus - BA, Brasil \\ Recebido em 14/12/06; aceito em 26/10/07; publicado na web em 2/7/08
}

\begin{abstract}
BUILDING KNOWLEDGE THROUGH WORK PROJECTS: AN EXPERIMENT IN THE CHEMISTRY COURSE OF THE STATE UNIVERSITY OF SANTA CRUZ IN BAHIA. In this work, we describe a pedagogical experiment using work projects in chemistry undergraduate programs in general chemistry and inorganic chemistry courses making learning more dynamic and consolidating the link between students and the external community. We highlight as fundamental outcomes the improvement in the learning process and, above all, the active participation of the students in investigation and problem-solving activities.
\end{abstract}

Keywords: projects; higher education; chemistry.

Mudanças na prática pedagógica, certamente, envolvem mudanças nas concepções básicas do professor e têm consequiências no currículo, na avaliação e na organização geral do curso. Portanto, qualquer tentativa de mudança na prática deverá estar inserida em uma proposta maior de mudança. ${ }^{1}$ Até pouco tempo, o professor, no decurso de sua formação, aprendia que a função da escola era a de ensinar e o seu papel era o de transmitir o maior número de informações em um menor tempo possível. Isto porque este modo de ensinar estava sustentado em uma concepção de aprendizagem por meio da qual a informação é considerada igual a conhecimento. Para muitos professores, quando se passa uma informação e o aluno a memoriza, supõe-se que o aluno aprendeu algo. Assim, quanto mais o indivíduo consegue desenvolver a informação em conformidade com o que lhe foi dado, mais se acredita que a aprendizagem ocorreu. ${ }^{2}$

Tal concepção de ensino, baseada na transmissão de informações, está muito presente nos cursos superiores, principalmente em áreas nas quais são contratados especialistas em determinada área do conhecimento, com pouco ou nenhum conhecimento de práticas pedagógicas, capazes de interpretar adequadamente os desafios constantes que se apresentam no desenvolvimento de sua atividade docente. Não bastam apenas mudanças curriculares, equipamentos da mais moderna tecnologia, escolas bem estruturadas — entre outros fatores —, se o professor, que é o responsável por conduzir o processo "ensino e aprendizagem", não estiver preparado para atuar neste novo contexto escolar. Hernández salienta que as inovações ou são assinaladas pelos professores ou acabam não acontecendo. ${ }^{3}$

Embora o discurso pedagógico atual apresente como objetivo de ensino a formação de alunos autônomos, conscientes, reflexivos, participativos, cidadãos atuantes, e não apareçam, neste discurso, características como passividade, submissão ou alienação, a preocupação maior do professor é com a transmissão de conteúdos disciplinares prontos e acabados, não permitindo a abertura de discussões sobre o desenvolvimento da disciplina ou dos conteúdos por ela abordados, pois isso significaria perda de tempo e o não vencimento do programa ao final do semestre.

Por outro lado, ao tentar modificar esta realidade, muitos pro-

*e-mail: ejwartha@uesc.br fessores acabam negando ou desvalorizando os conteúdos disciplinares. O grande erro que se comete nesta tentativa ${ }^{4}$ é que não se pode separar a aprendizagem dos conteúdos disciplinares do processo de participação dos alunos, nem desvincular as disciplinas da realidade atual.

\section{OS PROJETOS DE TRABALHO COMO PROPOSTA DE MUDANÇA NA ABORDAGEM DAS AULAS DE QUÍMICA GERAL E INORGÂNICA}

O desenvolvimento de projetos a partir de um tema gerador ou de um problema aparece como uma das alternativas para as questões apontadas, pois permite aos alunos analisar e resolver problemas, vivenciar situações e acontecimentos dentro de um contexto, utilizando conhecimentos das disciplinas da sua experiência sóciocultural. O trabalho com projetos traz uma nova perspectiva para entendermos o processo de ensino e aprendizagem. O trabalho com projetos ou o método de projetos tornou-se conhecido, no Brasil, a partir da divulgação do movimento conhecido como Escola Nova, contrapondo-se aos princípios e métodos da escola tradicional. Esse movimento foi fruto das pesquisas de grandes educadores como Montessori, Decroly, Claparède e outros, e teve na América do Norte John Dewey e Willian Kilpatrik construindo as bases da chamada Pedagogia Ativa. Neste contexto e dentro desta polêmica é que surge a Pedagogia de Projetos. Reinterpretando esse movimento nas últimas décadas, Hernández ${ }^{3}$ discute e apresenta uma proposta de organização do currículo através de projetos de trabalho.

A Pedagogia de Projetos de Dewey e Kilpatrick, ${ }^{5}$ considerada então um método, passa agora a ser vista mais como uma postura pedagógica na qual a aprendizagem é desencadeada a partir de um problema que surge e que conduz à investigação, busca de informações, construção de novos conceitos, seleção de procedimentos adequados. O "projeto de trabalho" está vinculado a esta linha da pedagogia ativa, como uma das várias formas da Pedagogia de Projetos. Para Hernández, ${ }^{3}$ os projetos de trabalho contribuem para uma re-significação dos espaços de aprendizagem, de tal forma que eles se voltem para a formação de sujeitos ativos, reflexivos, atuantes e participantes.

O projeto de trabalho é pouco utilizado como forma de abordagem metodológica nos cursos de Química nas universidades. Fo- 
ram poucos os relatos deste modelo de abordagem didática encontrados na literatura. Menezes e Farias ${ }^{6}$ relatam a utilização da Pedagogia de Projetos com o tema de monitoramento ambiental no ensino da Química Analítica, Bioquímica e Microbiologia, no âmbito do estudo da qualidade da água no município de Divinópolis, no estado de Minas Gerais. Lisboa e Ydi ${ }^{7}$ apresentam a aplicação de uma proposta para o desenvolvimento integrado das disciplinas de Química Analítica e Química Inorgânica, no qual foi desenvolvida uma série de projetos abordando temas como a água do mar, conchas de moluscos, fixador de fotografia, sucatas de ferro, pilhas comuns usadas, resíduos de laboratório, entre outros. Vários professores de Química australianos e neozelandeses ${ }^{8-10}$ desenvolveram e orientaram projetos nas aulas experimentais dos cursos de Química da Austrália e Nova Zelândia, abordando questões ambientais e o uso de novas tecnologias na determinação de poluentes atmosféricos, entre outros. Arroio et al. ${ }^{11}$ desenvolveram, na perspectiva de projetos, o ensino de Química Quântica com o auxílio de computadores na abordagem do tema Fármacos. Alunos do Curso de Graduação em Química da Curtin University of Techonology são orientados, a partir do sexto semestre, a planejar e executar um projeto de investigação sistemática em Química Orgânica, Inorgânica, Analítica ou de Físico-Química. ${ }^{12}$ Todos destacam, como fundamental, a participação ativa dos estudantes, aprendizagem mais significativa e, principalmente o envolvimento dos estudantes em atividades de investigação e resolução de problemas, geralmente de modo cooperativo e com uma margem considerável de autonomia e responsabilidade.

\section{PROJETOS DE TRABALHOS NO CURSO DE QUÍMICA DA UESC (UNIVERSIDADE ESTADUAL DE SANTA CRUZ)}

A atividade didática com projetos de trabalho foi desenvolvida com 30 estudantes do Curso de Licenciatura em Química da Universidade Estadual de Santa Cruz no $2^{\circ}$ semestre letivo de 2005. Procurou-se, nesta atividade, integrar as disciplinas de Química Geral II (teórica e prática) e Química Inorgânica I (teórica e prática).

O objetivo dessa atividade foi buscar alternativas no sentido de permitir a superação de dicotomia teoria-prática tão presente nos cursos de Química. Buscou-se, também, superar o isolamento entre as disciplinas a fim de aprofundar e sistematizar os conteúdos disciplinares apontados como necessários para o desenvolvimento do projeto, respeitando diferentes estilos e ritmos de trabalho dos alunos, buscando uma aprendizagem mais significativa.

Todavia, salientamos que o trabalho com projetos tem uma série de efeitos colaterais ${ }^{13}$ que devem ser evitados. Alguns alunos se sentem perdidos quando as aulas não são conduzidas da maneira tradicional. Outros se sentem incapazes de realizar um projeto ou apresentam dificuldades de trabalhar em equipe. No trabalho com projetos, a quantidade e a qualidade de conteúdos específicos das disciplinas que determinado grupo de alunos adquire são diferentes dos adquiridos por outro grupo de alunos, ou seja, a aprendizagem não é uniforme nem mesmo entre membros de um mesmo grupo.

Escolhemos estas disciplinas, primeiro por sermos os professores dessas disciplinas; segundo, por sentirmos a necessidade de romper com uma prática que não favorece a aprendizagem de nossos estudantes, mostrando como uma nova postura na prática docente pode romper com a visão tradicional, analítico-reducionista, que fragmenta a Química cada vez mais em áreas e disciplinas e se contrapõe a uma visão mais holística, hoje indispensável para a compreensão do mundo. Também, por serem disciplinas do início do curso e apresentarem características favoráveis ao trabalho com projetos.
O conteúdo programático das disciplinas de Química Geral II e de Química Inorgânica I nos curso de graduação em química geralmente aborda os tópicos ou conceitos relacionados em suas ementas:1- Investigando as soluções aquosas; 2- Solubilidade de compostos em água; 3-Compreendendo as reações em soluções aquosas; 4- Princípios de reatividade: cinética química; 5- Princípios de reatividade: equilíbrios químicos; 6- A química dos ácidos e bases.

Portanto, projetos que abordem o tema água, além de propiciarem uma aprendizagem mais significativa destes conceitos, também permitem uma abordagem diferente, sem a necessidade de abrir mão de tópicos de conteúdos importantes.

Projetos de trabalho abordando a questão da água permitiram não só trabalhar com as habilidades cognitivas, mas também com aquelas relacionadas a habilidades atitudinais e procedimentais. A avaliação, neste caso, necessita, também, abranger estas três dimensões: - Cognitivas: verificação da aprendizagem de conceitos relacionados a ementas das disciplinas, por meio de provas pontuais para todos os alunos, como era realizada nos anos anteriores, e o uso dos conceitos em outras situações; - Atitudinais: verificação da capacidade de argumentar, manifestar e defender opiniões, seja de forma oral ou escrita, e na competência para analisar e avaliar o seu próprio trabalho através de relatos das atividades realizadas a cada semana pelo grupo (portfólio); - Procedimentais: observação e intervenção na capacidade de os alunos trabalharem em grupo, da criatividade e habilidade de discutir e propor alternativas na solução de problemas. Também observamos a organização das atividades, a distribuição das tarefas entre os membros do grupo e a organização e discussão dos dados levantados.

O tema escolhido foi a Bacia do Rio Cachoeira e sua região estuarina, devido à sua relevância para a vida cotidiana da região, à atualidade do assunto e sua relação com as diversas áreas do conhecimento que fazem parte do conteúdo programático das disciplinas.

As linhas gerais que nortearam o desenvolvimento dos projetos de trabalho podem ser assim sintetizadas: Escolha do tema; Reconhecimento do campo de pesquisa; Pesquisa bibliográfica sobre o tema; Elaboração do projeto inicial; Discussão do projeto inicial; Execução do projeto; Elaboração do relatório preliminar; Discussão do relatório; Apresentação do relatório final

Após o contato inicial com o objeto de estudo, foram apresentadas e discutidas, com os alunos, notícias e denúncias encontradas nos meios de comunicação, as quais abordavam questões relacionadas ao uso irracional da água ao longo da Bacia do Rio Cachoeira. Questões relacionadas ao tratamento de esgotos, de resíduos industriais, da poluição e das ações realizadas ao longo do tempo pelos órgãos competentes e pela população em geral.

Além disso, organizamos e sistematizamos, junto com os alunos, os conceitos que seriam necessários para a compreensão do problema, agora através dos óculos da Química. Apresentamos e discutimos o mapa conceitual, Figura 1, para que cada grupo definisse seu tema de estudo para desenvolver um projeto de trabalho que tivesse como objeto de estudo a Bacia do Rio Cachoeira, e que ao mesmo tempo aprofundasse e sistematizasse conceitos científicos relevantes à compreensão do fenômeno.

O mapa conceitual possui o objetivo de organizar e representar um conjunto de conhecimentos e as relações entre os conceitos. Não que os conceitos sejam trabalhados de forma linear, mas existe, sim, uma relação entre eles, e dentro dos projetos de trabalho, à medida que fossem sendo necessários, eles seriam aprofundados em sala de aula. O mapa conceitual tem a vantagem de dirigir a atenção, tanto do aluno como do professor, sobre um número de idéias e conceitos importantes, nos quais se deve concentrar qual- 
quer tarefa específica do projeto em andamento. Uma vez realizado o trabalho, tendo sido executado o projeto, o mapa conceitual proporciona um resumo esquemático dos conceitos abordados durante a elaboração e execução do projeto. ${ }^{14}$ Ao elaborar e re-elabo-

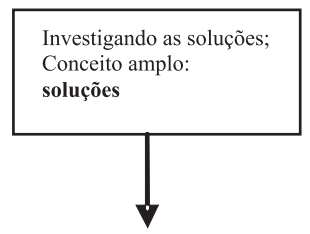

Compreendendo as diferentes

solubilidades de compostos em água; Conceito amplo: solubilidade
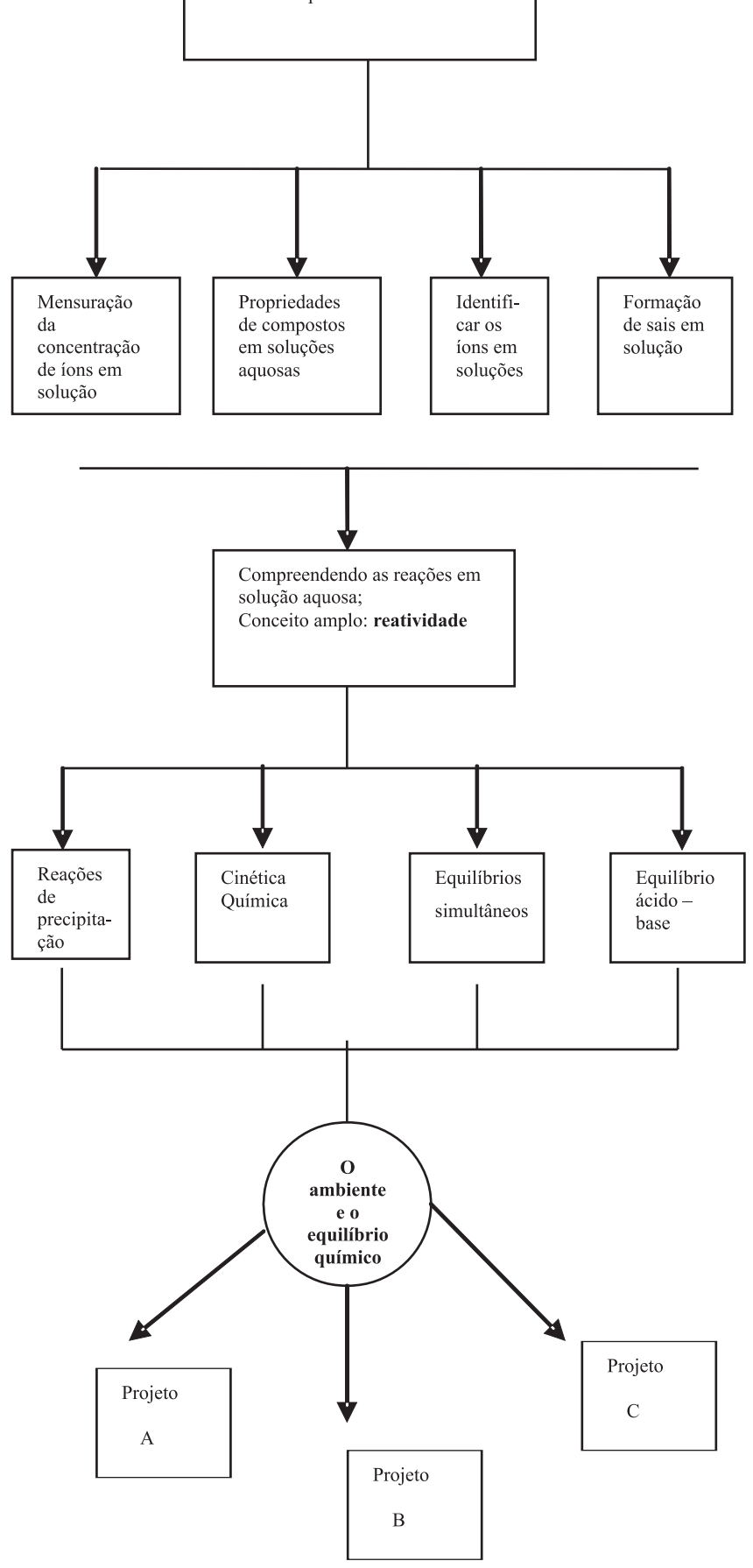

Figura 1. Mapa conceitual dos conteúdos disciplinares rar mapas conceituais, professores e alunos desenvolvem novas relações conceituais, e por isso constroem novos significados ${ }^{15}$ (pelo menos significados que não possuíam de forma consciente).

Os grupos foram formados espontaneamente com no máximo 4 componentes em cada um. Cada grupo teve autonomia no desenvolvimento de seu projeto. Os projetos desenvolvidos pelos estudantes foram: i) Análise de cromo nas águas do Rio Cachoeira; ii) Análise de resíduos totais, resíduos fixos e determinação do oxigênio dissolvido na água do Rio Cachoeira; iii) Efeitos da maresia sobre metais expostos nas praias de Ilhéus; iv) Análise de íons cálcio e magnésio nas águas do mar, do Rio Cachoeira e na região de estuário; v) Identificação da presença de íons de ferro, magnésio e iodo nas águas do Balneário de Tororomba; vi) A indústria têxtil em Itabuna e a presença de metais pesados na água do Rio Cachoeira; vii) Absorção de metais pesados através de plantas aquáticas: o caso das baronesas e o metal cádmio; viii) Análise de coliformes fecais em diferentes amostras de água Rio Cachoeira.

O que caracterizou cada projeto não foi a origem do tema, mas o tratamento dado a ele, no sentido de tornar uma questão particular de um grupo como um problema de todos. Portanto, foi possível envolver os alunos no processo de construção, reflexão, participação, cooperação e articulação, propiciando um envolvimento maior dos alunos durante o curso. No desenvolvimento do projeto utilizamos a carga horária total de todas as disciplinas envolvidas. Após a escolha do tema, partiu-se para a construção do projeto e a busca do referencial teórico no qual se identificavam conceitos fundamentais a serem aprofundados. Os conceitos fundamentais estão relacionados na Figura 1. Com o projeto construído e após um estudo sistematizado dos conceitos, partiu-se para a execução. Nesta etapa realizou-se a coleta e armazenamento das amostras, planejamento e preparo dos reagentes e materiais necessários à realização dos experimentos. Os alunos foram orientados a registrar todos os dados, a organizar tabelas e gráficos dos resultados e, finalmente, a discutir seus resultados a partir de um modelo científico.

$\mathrm{Na}$ execução desta atividade, além da carga horária das disciplinas, foi necessário que os professores envolvidos nos projetos disponibilizassem $2 \mathrm{~h}$ semanais para o acompanhamento individual deles.

No acompanhamento dos projetos os docentes levaram em consideração algumas características a serem avaliadas nos projetos, ${ }^{16}$ como: 1 - O título está adequado ao estudo realizado? 2 - A introdução procura inserir o problema proposto no processo de produção do conhecimento na área? 3 - As questões atuais relevantes para o problema são tratadas? 4 - As lacunas e/ou contradições (entre resultados de diferentes pesquisas; entre teorias e resultados de pesquisas; entre o problema e as abordagens metodológicas utilizadas) são discutidas com o objetivo de indicar de onde se originou o estudo proposto? 5 - O objetivo (ou questão central) do estudo é enunciado de forma clara e concisa? 6 - As questões e/ou hipóteses são claramente formuladas? 7 - Os pressupostos conceituais são explicitados? 8 - As fontes bibliográficas utilizadas são adequadas em termos de qualidade e atualidade? 9 - Os procedimentos metodológicos são adequados e suficientes para responder às questões propostas e/ou para testar as hipóteses de estudo? 10 - Os instrumentos utilizados para a coleta de dados são apropriados aos objetivos ou questões? 11 - Os resultados respondem às questões propostas? 12 - As interpretações e conclusões se apóiam nos dados apresentados? 13 - As idéias são apresentadas com clareza e organização? 14 - As atividades foram realizadas de acordo com o cronograma estabelecido? 15 - Houve interação entre todos os membros do grupo na realização do projeto?

Todos os projetos foram avaliados pelos docentes e pelos estudantes na forma de um portfólio. O portfólio possibilita avaliar as 
capacidades de pensamento crítico, de articular e solucionar problemas complexos, de trabalhar colaborativamente, de conduzir pesquisa, de desenvolver projetos e de o aluno formular os seus próprios objetivos para a aprendizagem. ${ }^{17} \mathrm{O}$ professor e o próprio aluno avaliam todas as atividades executadas durante o desenvolvimento do projeto de trabalho, levando em conta toda a trajetória percorrida. Não é uma avaliação classificatória nem punitiva. Analisa-se o progresso do aluno. Valorizam-se todas as suas produções: analisam-se as últimas comparando-se com as primeiras, de modo que se perceba o avanço obtido. Isso requer que a construção do portfólio se baseie em propósitos de cuja formulação o aluno participe, para que se desenvolva o sentido de "pertencimento".

No desenvolvimento dos projetos o trabalho com o portfólio tem-se apoiado em seis princípios básicos: a construção pelo próprio aluno, possibilitando-lhe fazer escolhas e tomar decisões; a reflexão sobre as suas produções; a criatividade, porque o aluno escolhe a maneira de organizar o portfólio e busca formas diferentes de aprender; a auto-avaliação pelo aluno, porque ele está permanentemente avaliando o seu progresso; a parceria professor-aluno e entre alunos, eliminando-se ações e atitudes verticalizadas e centralizadoras; a autonomia do aluno perante o trabalho. ${ }^{18}$

\section{RESULTADOS E DISCUSSÃO}

Na dinâmica do trabalho com projetos foi possível estabelecer com os estudantes uma relação mais próxima, uma relação de confiança, pois na articulação das informações com o conhecimento, no processo de orientação e mediação do processo de ensino e aprendizagem, há uma superação do paradigma dominante, no qual o professor é visto como o dono do saber, para uma relação de reciprocidade, na qual o professor passa a estudar junto com os alunos, discutindo alternativas, métodos e viabilidades.

Outro fator que também foi possível identificar no trabalho com projetos diz respeito à avaliação. Nas provas tradicionais, pelas quais se avalia o conhecimento específico do conteúdo, a maioria dos estudantes apresentou boa compreensão dos conceitos, visto que teve bom rendimento. Entretanto, foi na análise dos portfólios coletivos que se verificou que dificuldades apresentadas pelos estudantes na produção de textos, no trabalho em grupo, na organização de práticas experimentais, tanto na fase de elaboração do projeto quanto na fase de execução, iam sendo gradativamente superadas na medida em que os estudantes tomavam conhecimento de seus progressos, de suas necessidades e, principalmente, de suas dificuldades. Talvez, o melhor aspecto a ser observado no trabalho com projetos seja a capacidade de pensar juntos.

No trabalho com projetos, também, pudemos detectar alguns efeitos colaterais. Alguns alunos se sentem perdidos quando as aulas não são conduzidas da maneira tradicional. Registraram-se comentários como: "Quando é que vamos começar a estudar química geral?", "Até quando vai esta matação de aula?". Outros alunos se sentem incapazes de realizar um projeto: "Eu trabalho, não tenho tempo", "Não consigo trabalhar em grupo". Outro efeito colateral observado no trabalho com projetos é que a quantidade e a qualidade de conteúdos específicos das disciplinas, adquiridos por determinado grupo de estudantes, é diferente dos adquiridos por outros grupos, ou seja, a aprendizagem não é uniforme nem mesmo entre membros de um mesmo grupo. Entretanto, estamos convictos que desenvolvemos nestes alunos uma postura que certamente os levará a enfrentar com naturalidade problemas, e que terão condições de buscar e superar dificuldades que por ventura vierem no prosseguimento do curso.

Perkins ${ }^{19}$ nos diz claramente que, se não entendermos o aprendido, ele não servirá para nada. Aprendemos ao pensar com e pen- sar sobre o que estamos estudando. Aprender é uma conseqüência de refletir a respeito do que está sendo apresentado em sala de aula. O conhecimento só é realmente adquirido quando tem significado e podemos pensar usando o que foi aprendido.

\section{CONCLUSÕES}

A utilização do trabalho através de projetos criou situações de estudo muito favoráveis ao aprendizado significativo. A observação e estudo da realidade concreta geraram a necessidade de buscar o conhecimento técnico para respaldá-lo e criar instrumentos de diagnóstico e ação. A inserção dos alunos nos problemas locais provocou uma maior interação da universidade com a comunidade externa.

O ensino da Química através dos projetos possibilitou, na medida do possível, a superação do paradigma relacionado com dicotomia teoria-prática, muito presente nos cursos de Química. Apesar de, no início, ter-se observado que os estudantes estavam um pouco "espantados" e até mesmo preocupados com a forma de abordagem das disciplinas, devido ao fato de estarem muito preocupados com a "nota" e com a ampliação do tempo necessário para a execução do projeto, verificou-se, no decorrer do desenvolvimento dos projetos, uma mudança de postura e de atitude perante a nova proposta de trabalho e a forma como eram conduzidas as discussões e suas relações com o conhecimento cientifico.

Conclui-se que é perfeitamente possível trabalhar com projetos de trabalho sem abrir mão de conteúdos importantes, desde que haja disposição, por parte do professor, de aplicar e estar aberto para flexibilizar ações mediante situações imprevistas.

Ao término desta etapa pode-se perceber claramente que os alunos demonstraram um interesse maior pelo curso. Nesta turma, até o momento não tivemos nenhum aluno evadido, fato que é muito comum em nosso curso, e cremos que também em outros cursos de Química.

Concordamos com Dubois ${ }^{12}$ quando este afirma que o trabalho com projetos apresenta uma série de vantagens quando comparado às formas mais tradicionais de ensino. Em primeiro lugar, porque dá significado ao conhecimento, uma vez que os estudantes têm papel primordial no desenvolvimento do projeto. Em segundo lugar, porque, ao envolver-se em um projeto, professores e estudantes passam, necessariamente, a ter interesses semelhantes e a interação pessoal fica mais intensa, o que raramente acontece no sistema de ensino tradicional. Em terceiro lugar, porque dá oportunidades inestimáveis de que o conhecimento tácito dos alunos possa emergir e ser discutido.

Apesar das dificuldades encontradas na elaboração e execução dos projetos, devido à falta de materiais de pesquisa, de equipamentos e reagentes adequados no laboratório, a maioria dos grupos obteve resultados significativos. Todavia, os resultados mais significativos não estavam na identificação positiva de determinados íons em solução ou na identificação ou não de coliformes fecais na água do Rio Cachoeira; estavam, sim, no fato de que os conceitos químicos e métodos analíticos usualmente trabalhados de maneira fragmentada, como unidades dentro das disciplinas, passaram a ser naturalmente necessários ao andamento do projeto, tornando desta forma o conhecimento mais significativo. As atividades experimentais, as famosas "receitas de bolo", onde o aluno recebe um roteiro, devendo segui-lo à risca para chegar a resultados já previstos, foram substituídas pela atividade de execução dos projetos, onde os roteiros experimentais são construídos, testados e executados pelos alunos. Também não se encontram mais os reagentes preparados e os materiais e equipamentos devidamente organizados, passando agora este processo a ser responsabilidade 
de cada grupo. Nesta etapa, foi possível perceber junto aos grupos o desenvolvimento da capacidade de trabalhar em equipe, de tomar decisões, de refletir sobre a atividade, de formular e resolver problemas e desenvolver o processo de aprendizagem de forma cooperativa. Não podemos negligenciar o papel do professor, ele é fundamental, mas como questionador, lançando dúvidas, acompanhando de perto o trabalho de cada grupo, intervindo quando necessário. O professor faz papel de mediador, de modo a levar o aluno a encontrar o melhor caminho para resolver seu problema.

\section{AGRADECIMENTOS}

A todas as pessoas que de forma direta ou indireta contribuíram para tornar possível este trabalho, à UESC e ao DCET, que tornou possível a realização deste trabalho.

\section{REFERÊNCIAS}

1. Moraes, M. C.; O paradigma educacional emergente, Papirus: Campinas, 1997.

2. Alonso, M.; Masseto, M.; Formar educadores para um mundo em transformação, Conferência na PUC-SP, São Paulo, 1998.

3. Hernandez, F.; Transgressão e mudanças na educação: os projetos de trabalho, Artes Médicas: Porto Alegre, 1998.

4. Leite, L. H. A.; Presença Pedagógica 1996, 2, 24.
5. Cunha, M. V.; John Dewey: Uma Filosofia para Educadores em Sala de Aula, Vozes: Petrópolis, 1999.

6. Menezes, H. C.; Faria, A. G.; Quim. Nova 2003, 26, 287.

7. Ydi, S. J.; Lisboa, J. C. F.; Revista Fundação Santo André 2003, 2, 97.

8. Barrie, S.; Buntine, M.; Jamie, I.; Kable, S.; Aust. J. Ed. Chem. 2001, 57,

9. Barrie, S.; Buntine, M.; Jamie, I.; Kable, S.; APCELL: Developing Better Ways of Teaching in the Laboratory, Proceedings of Research and Development into University Science Teaching and Learning Workshop, Uniserve Science; University of Sydney: Sydney, 2001.

10. Barrie, S. C.; Bucat, R. B.; Buntine, M. A.; Crisp, G. T.; George, A. V.; Jamie, I. M.; Kable, S. H.; Read, J. R.; Chem. Educ. Res. Pract. 2007, 8 , 232.

11. Arroio, A.; Homem-de-Mello, P.; Honório, K. M.; Silva, A. B. F.; Weber, K. C.; Quim. Nova 2005, 28, 360.

12. http://chemistry.curtin.edu.au/teaching/portfolio/innovation.cfm, acessada em Maio 2007.

13. http://tecfa.unige.ch/ laurent/didact/projet.htm, acessada em Janeiro 2006.

14. Moreira, M. A.; Cadernos de Aplicação 1998, 11, 143

15. Moreira, M. A.; Cienc. Cult. 1980, 32, 474.

16. Alves-Mazzotti, A. J.; Gewandsznajder, F.; O método nas ciências naturais e sociais: pesquisa quantitativa e qualitativa, $2^{\mathrm{a}}$ ed., Pioneira: São Paulo, 1999.

17. Murphy, S. Em Situating portfolios: four perspectives; Yancey, K. B.; Weiser, I., eds.; Utah State University Press: Logan, Utah, 1997, cap. 2.

18. Villas-Boas, B. M. F.; Educ. Soc. 2005, 26, 2910.

19. Perkins, D.; Smart Schools - from training memories to educating minds, The Free Press: New York, 1992. 